\title{
Exploring positive working relationships in light of the aims of probation, using a collaborative approach.
}

\section{Sarah Lewis}

Doctoral Student/Programme Facilitator

Acknowledgements

Thank you to Mike and all those that supported and participated in this research. Your contributions and insights were invaluable.

This article begins to consider the factors that promote the formation of a positive working relationships (PWR) between practitioner and probationer. The results from a pilot study are used to review the importance of "assist, advice and befriend" and "confront, challenge and change" within current practitioneroffender relationships. Through collaborative design, five probationers completed visual narratives to explore significant PWR's with criminal justice professionals and 36 probation staff completed a questionnaire to examine their beliefs around PWR's with probationers. The results highlight the benefit of demonstrating a genuine belief in probationers' capacity to change and are discussed in light of the literature.

Keywords: positive working relationship, probationers, visual narratives, collaborative approach, probation.

\section{Introduction}

A positive working relationship (PWR) between probation practitioner and probationer has been considered a vital ingredient within correctional work and it's importance has 
recently re-emerged through the growing interest of probationer engagement initiatives. NOMS (2010) has recently reiterated the importance of a PWR between practitioner and probationer stating; “...the relationship between offender and practitioner can be a powerful vehicle for changing behaviour and reducing re-offending" (NOMS, 2010.) Whilst the staff-probationer relationship has been recognised as an important aspect of offender rehabilitation, little is known about the processes underlying this relationship and what factors matter to the probationer.

This article reiterates the importance of "the relationship" within correctional work by reviewing the findings from a pilot study carried out to explore significant relationships with Criminal Justice (CJ) professionals and identifying those individuals that successfully developed meaningful relationships with probationers. By doing this, it hopes to shed some light on what attributes of CJ professionals were of significance by considering "what works" in assisting probationers to make positive changes in their life. Further to this, probation practitioners were asked to explore their beliefs around PWR's in order to gain a different perspective on the issue and begin to explore how these views may differ from that of the probationer.

This article will begin by reviewing what is meant by a PWR and go on to review the aims of probation in relation to the practitioner-probationer relationship. The findings from a pilot study will be discussed in light of these aims with the objective of exploring the future direction of probation in respect to working relationships.

A collaborative approach was embraced throughout the pilot study, considering the participants as "experts" (Atkinson, 1998) and providing a number of opportunities for both probation staff and probationers to discuss the research in light of their experiences. This embraced an emancipatory approach that was described by Robson 
(2002) which focuses upon the experiences of the participants, where the researcher and participant were considered as equals within the research. I adopted this approach with the hope to gain insight from the life stories of probationers as well as the perceptions of probation staff. Further to this I wanted to highlight the importance of the probationer's "voice" within research and this approach would create a robust piece of research that was evaluated by many in order to uphold greater integrity and credibility.

I worked collaboratively with an ex-probationer to inform the research at every stage from design to data analysis. This involved designing and reviewing the visuals for the narrative interviews, discussing how the research techniques could be made accessible to the samples and exploring the data together to verify my interpretations of the interviews. Also, the findings from the visual narrative interviews informed the questionnaire design that was administered to probation staff by exploring some of the themes that transpired from the interviews and a post-interview questionnaire was given to probationers to explore the data in greater depth. It would seem logical to adopt this approach due to the topic in question and upon reflection, this was invaluable to the outcomes of the research and methods that were developed.

\section{The Working Relationship}

PWR's have been defined using various terms including a "therapeutic relationship" (Lambert and Barley, 2001) and a "working alliance" (Bordin, 1979). Elvins and Greena (2008) considered a therapeutic alliance to be the extent to which a client and therapist work together and this aspect of collaboration remains a significant facet to a PWR when working with probationers. Within the field of psychotherapy, the positive relationship between therapist and client has consistently predicted positive treatment 
outcomes (Martin, Garske and Davis, 2000; Stewart and Picheca, 2001) though from reviewing the literature in relations to criminal justice, three themes are prominent. Firstly; Elvins and Greena (2008) identified that a therapeutic alliance can take place between any two individuals. Secondly; from Ilgen, McKellar, Moos and Finney's (2006) work; a PWR may gain greater relevance when working with those that exhibit low levels of motivation. And thirdly, a therapeutic alliance with the offending population is a key factor contributing to positive change (Rossa, Polascheka \& Ward, 2008; Rex, 1999; Dowden \& Andrews, 2004).

The aims of probation have evolved over the last century, focusing originally upon the trinity of "assist, advise and befriend" and later moving towards that of "confront, challenge and change" (Barry, 2007.) The rise of manageralism and political shift to punishment and control considerably altered the role of the probation officer from social worker to offender manager (OM). As a result of this, the emphasis on a PWR was shifted from offender management to interventions following the "what works" initiative that focused upon risk, need and responsivitiy (Bonta \& Andrews, 2007). The concept of building and forming a relationship with a probationer was consequentially assigned to the role of partnership interventions and programmes, leaving the offender manager to coordinate sentence plans and carry out enforcement in the event of noncompliance. As a result of this, probation officers were required to adopt new skills and knowledge that led to several consequences for the practitioner. For example, Partridge (2004) described how the probation officer experienced lower levels of job satisfaction and believed they had been de-skilled, as they were required to rely upon explicit knowledge grounded in the "what works" principles rather than tacit knowledge (Newman and Nutley, 2003). 
In light of the political shift towards "confront, challenge and change", Barry (2000) argued the staff-probationer relationship was threatened and called for staff to listen effectively to those that they work with. However, as demands increase and staffing levels reduce due to financial constraints, probation staff will be challenged in developing PWR's with those they work with to encourage change and reduce the likelihood of re-offending. Probation staff are spending a significant amount of time carrying out tasks that distract them away from this aspect of their role and it has been highlighted by Gregory (2010) that high caseloads undermines the working relationship that probation staff can have with a probationer.

In the early 2000's, the theories relating to desistance (Maruna, 2000) and the good lives model (Ward, 2002) contributed to the re-emergence of the working relationship between practitioner and offender. Bourgon, Gutierrez and Ashton (2011) encouraged the need for a more active and direct interaction, whereupon staff should act as a "change agent" by taking on a more therapeutic role within their work. Clark (2005) promoted this concept of the probation officer becoming a more therapeutic player and suggested the need for therapeutic abilities to be considered at the point of recruitment. Most significantly, the findings from Dowden and Andrews' (2004) meta-analysis encouraged the practitioners to focus more upon the working relationship through the components of "core correctional practice" which emphasised the importance of forming and sustaining a PWR through a warm, genuine and respectful interaction with the offender.

This latter interest in PWR's led to the establishment of the Offender Engagement Programme within the National Offender Management Service (NOMS) in 2010 that stated "the one to one relationship between offender and supervisor can be a powerful 
vehicle for change to reduce reoffending" (Copsey, 2011). In light of the relaxation of National Standards, probation staff have been encouraged to draw upon the desistance research and focus upon "meaningful engagement" (NOMS, 2011), reinforcing the need for pro-social modelling and relationship building specifically. In the future, the piloted initiatives in Professional Judgement and Skills for Effective Engagement and Development (SEEDS) offer new challenges for probation staff with respect to the acquisition and use of knowledge and skills in practice and emphasis on reflective practice.

This article argues that irrespective of the aims of probation, there is a necessity for practitioners to encourage mutual respect and honesty with those they work with, as well as demonstrating a genuine belief in the probationers' ability to change. If collaborative working is present within a practitioner-probationer relationship, then promoting self-confrontation, as described by Miller and Rollnick (2002), is an effective way to challenge negative behaviour and encourage change. This approach is supported by the work of Chui (2003) who suggested that a working relationship must include the concepts of friendliness, though be balanced with honesty and direct confrontation around offending behaviour.

\section{Research Aims}

This article hopes to explore "the relationship" from a frontline perspective, drawing on the views and experiences of both probationers and probation practitioners. The overall aim of the pilot study was to explore what promotes the formation of a PWR between practitioner and probationer in light of the aims of probation. A further objective was to explore the importance of staff characteristics when working with probationers with the hope to encourage probation staff that there are numerous 
benefits of taking the time in developing PWR's with their probationers. The pilot study was the initial step within a broader research agenda that ultimately aims to investigate factors that both promote and inhibit a PWR from forming and begin to explore the processes that lie behind this formation. The rationale of this research is to uncover how probation staff can effectively build a PWR with probationers and safeguard it when this relationship is threatened.

\section{Methodology}

The research methodology adopted a mixed methods approach using visual narratives to explore past working relationships experienced by probationers and a questionnaire to capture the beliefs of probation staff. The sample was purposive in nature, drawing upon five probationers that had demonstrated a strong motivation to move away from crime and who had over ten years "experience" of the CJ Service. The participants were all male, from a range of ethnic origins and had committed a spectrum of offences including; theft, drink driving, violence, drug offences and fraud/deception. It should be noted that the probationers were previously known to the researcher and were approached individually to partake in the research after their completion on the Thinking Skills Programme. From an ethical perspective, the recruitment may have led to both a bias in the responses made by probationers and role conflict for myself. To minimise these risks, I made these issues clear to all participants through informed consent and clarified my role as a researcher prior to the interviews commencing.

A narrative methodology was chosen in light of Atkinson's (1998) comments of increasing our knowledge of the world through the telling of a story. Also, Maruna (2000) highlighted the benefits of using a narrative structure with offenders to develop self-identity and gain a greater understanding of the past. A number of visual 
techniques were explored to inform the design (e.g. Tagg, 1985; Young and Tardif, 1988, Labov and Waletzky, 1997) and mind maps were adopted following Reason's (2010) research, with the aim of creating an accessible and responsive visual experience. From my work as a programme facilitator, I valued an interactive technique that was engaging, motivational and thought-provoking, so formulated a design collaboratively that could achieve this. I wanted the probationers to interact with the visual aids during the interview and take ownership of the interview. In order to achieve this I worked with both probation staff and an ex-probationer to design the visual and used their feedback to refine the visuals so that they were simple and easy to understand. The reason for taking this approach was to ensure that the probationers fully engaged in the research and enjoyed taking part in it, gaining insights into their relationships as well as discussing these experiences with me.

During the interviews, probationers were asked to broadly identify "chapters" within their lives and plot them on a timeline. They were then asked to consider times in their lives where positive change took place and describe the three most significant CJ professionals who effectively encouraged these changes. The positive characteristics of the CJ staff were elicited on three separate mind maps that were linked back to the timeline, to establish where the relationships began. These characteristics were collated from the narrative interviews and a literature review was carried out to inform the questionnaire phase of the study.

Probation staff were then given the ten most cited characteristics associated with a "therapeutic relationship" or "alliance", from forty-six studies and the narrative interviews and were asked to rank these from least to most important. For the questionnaire, the sample consisted of sixteen staff from Offender Management (OM) 
and twenty programme staff within my local Trust. A short one-page questionnaire was used to capture staff perceptions of PWR's within practice. I wanted the questionnaire to be short due to the time pressures of probation practitioners and to feature both qualitative and quantitative responses to engage the participants. Due to the flexibility of questionnaire design, both open and closed questions were used and staff were asked details about their role within the organisation and length of service. Staff were asked to describe a PWR and rate on a Likert scale (1-5) how important they considered a PWR was when considering positive change in probationers and how essential they believed it to be within their own work. The questionnaire was evaluated by four probation practitioners from different operational levels and their feedback informed the design in relation to both wording and content. I felt this enabled me to iron out any ambiguities or problems prior to the main phase of data collection.

\section{Findings and Discussion}

The practitioner-probationer relationship will be discussed using the qualitative data as a means to explore the characteristics and the quantitative data to adopt a more explanatory role of these characteristics. Based on the small sample sizes within the pilot study the data is limited in relation to levels of generalisability, making the findings from the study tentative in nature.

\section{The practitioner-probationer relationship}

Both OM's and programmes staff viewed a PWR similarly, focusing upon a collaborative relationship that is based upon mutual respect and honesty. The following comments are from an OM and programme staff member when asked to define a PWR. They stated a PWR is: 
Offender manager: $\quad$ A relationship which is supportive, where there is mutual respect and honesty, whilst at the same time, clear boundaries are in place. (OM)

Programmes staff member: A relationship that has respect with it. A relationship that has understanding. A relationship that can be sustained and grow. A relationship that enables.

The concept of mutual respect and honesty were not only considered of importance by probation staff, but were characteristics that were discussed by the narrators. Here are two excerpts from the narrative interviews regarding the CJ staff in their lives who played a significant role.

Probationer 1: He was always fair, direct, told me how it was, how it is...he didn't mince his words. He wasn't aggressive and that is what he honestly believed.

Probationer 5: She started to trust in me, she started to believe in me and listen...she was so supportive...she showed me how to change...everything...the main thing there is that she listened to me.

When exploring the narrative data in light of the aims of probation, thirteen of the CJ figures were described with characteristics that could related to "assist, advise and befriend" (e.g. "caring", "a friend", "helpful", "gave advice") whilst nine possessed attributes that could be related to "confront, challenge and change" (e.g. "direct", "challenged me", "got that "too the point attitude."') Finally, when considering both aims in conjunction with the data, eight possessed characteristics which could be described with both. 
A further characteristic that featured within the narrative interviews was the concept of possessing a genuine belief in the probationer and their ability to change. For example, phrases from the narratives included: "he gave me hope," "he preserved," "she believed in me" and "she gave me self-belief." From the staff questionnaires, "giving advice" and "being direct" were considered as least important by the probation staff sample, though were stated frequently within the probationer sample when considering the PWR's that had been most significant in their lives. This supports the work of Chui (2003) who highlighted the need to combine friendliness with direct and honest confrontation. In order to effectively confront negative behaviours, honesty and respect are the corner stones of an effective PWR and these were present in those CJ individuals who were seen to have "worked" for the probationers. These findings also support those of Rex (1999), who found that probationers perceived the giving of advice as indicative of demonstrating concern for their wellbeing. This would suggest that the concepts of assistance and giving advice are still important values within probation, as they could be a mechanism by which belief can be communicated.

The findings would provisionally infer that both "assist, advise and befriend" and "confront, challenge and change" are beneficial, though it is argued that these cannot be effective without the presence of mutual respect and honesty. These were frequently stated characteristics within both samples and if present between practitioner and probationer, it is argued the probationer is more likely to be open to advice and assistance, as well as be more willing to listen to the challenges made regarding their negative behaviour. Enabling probationers to confront their own behaviour requires listening skills and respectful questioning as well as patience and persistence, all of which complement the theories underpinning motivational interviewing and the 
concept of self-confrontation. This also supports the work of Rex (1999) that highlighted the importance of a collaborative approach and commitment demonstrated by the practitioner to the probationer. It suggests that to "give advice" is an important feature of the PWR and this may be connected to how "giving advice" may indicate genuine concern, a trait that was elicited consistently during the narratives.

From drawing upon the quantitative data regarding the importance of specific characteristics (see Fig. 1), it was noted that when examining the mean scores from staff in programmes and offender management, programme staff viewed "empathy" and "warmth" and "respect" as more important compared to staff in offender management whilst offender management staff considered the characteristics of "giving advice," "honesty" and "flexibility" to be a greater significance in comparison to programme staff. Unfortunately due to the small sample size it was not viable to carry out statistical analysis on the data though the scores seem to reflect the differences between the two roles within probation work; programme staff focusing upon the core Rogerian attributes within their work and staff from offender management highlighting the importance of characteristics such as "honesty", that are congruent to their role in relation to aspects of risk management.

\begin{tabular}{|l|l|l|}
\hline Characteristics & $\begin{array}{l}\text { Programme Staff } \\
\text { (Mean Scores, N=15) }\end{array}$ & $\begin{array}{l}\text { Offender Management } \\
\text { (Mean Scores, N=16) }\end{array}$ \\
\hline Empathy & $\mathbf{7 . 4}$ & 5.7 \\
\hline Supportive & 6.6 & 6.6 \\
\hline Interest & 5.5 & 5.8 \\
\hline Flexibility & 3.7 & $\mathbf{4 . 7}$ \\
\hline Understanding & 5.8 & 6.2 \\
\hline Honesty & 6.7 & $\mathbf{7 . 9}$ \\
\hline Being Direct & 3.4 & 4.0 \\
\hline Giving Advice & 2.3 & $\mathbf{4 . 4}$ \\
\hline Respectful & $\mathbf{8 . 0}$ & 6.7 \\
\hline Warmth & $\mathbf{5 . 8}$ & 3.3 \\
\hline
\end{tabular}


Fig. 1. The mean scores relating to the importance of each characteristic $(10=$ most important, 1=least important) when comparing programme staff $(N=15)$ and staff from offender management $(N=16)$.

When staff were considered as a whole $(\mathrm{N}=31)$, the mean scores for the characteristics of "honesty" and being "respectful" were rated as most importance, though "giving advice" and "being direct" were rated as least important by the probation staff sample (See Fig. 2).

\section{Honesty $\quad 7.29$}

\section{Respectful $\quad 7.26$}

\section{Supportive $\quad 6.58$}

$\begin{array}{ll}\text { Empathy } & 6.53 \\ \text { Understanding } & 6.00 \\ \text { Interest } & 5.65 \\ \text { Flexibility } & 4.23 \\ \text { Being direct } & 3.71 \\ \text { Giving advice } & 3.39\end{array}$

Fig 2: The mean scores of each characteristic in order of perceived importance by probation staff (from most to least important (10=most important, 1=least important , $N=31$ )

When considering these findings in light of the aims of probation, it would suggest that to give advice and be direct does not appear to be of highest priority for probation staff, though it was recognised as significant by the probationer sample. It would be helpful in the future to investigate why probation staff consider "giving advice" and "being 
direct" to be less importance and how the political agenda has impacted upon this shift. It is particularly interesting that these were the two characteristics that were considered to "work" by probationers within the narratives. It may be the case that by creating an honest and respectful relationship between practitioner and probationer, the ability to give advice and be direct becomes circumstantial. Alternatively, how probation staff perceive "giving advice" and "being direct" may differ to how it is perceived by probationers, possibly with the connotation that "giving advice" could be considered "too soft" and "being direct", "too hard". Further work investigating the interaction of characteristics that are relevant to a PWR would be helpful in gaining a greater understanding of what mechanisms lie behind the formation of a PWR. The small sample size for the visual narratives limits the level of certainty regarding such claims, though it would appear that similar themes have been highlighted within the literature.

A simple bivariate correlation was also carried out to explore how length of service interacted with the staff scores relating to; a) how much of a priority forming a PWR was perceived to be and; b) how important a PWR is in contributing to positive change in probationers. It was found that overall, as length of service increased, the less of a priority staff perceived a PWR was within their work $(r(n=35)=-.424, p<=0.05)$ and the less important they believed it to be in relation to probationers making positive changes in their lives $(r(n=35)=-.336, p<0.05)$. It may be the case that due to the increasing caseload and limitations in respect to having time to develop PWR's, long serving staff may not perceive "change" in the same way that they once did under the social care model where they had flexibility, time and embraced the holistic approach. Under the social care model it may have made "change" more obvious compared to the offender 
management model that is now integrated within correctional work as probation staff were absorbed into every aspect of the probationer's life. On the other hand, new recruits essentially know no difference to the managerial environment in which they entered into having no point of comparison to draw from. When discussing this finding with an ex-probationer he stated that cynicism may contribute to this correlation, though without further exploration it is difficult to draw any firm conclusions. Further work to examine this tentative finding would be beneficial in the future to explore the reasons behind it and reveal whether our faith does indeed reduce, we compare the old with the new or even move from idealist to realist.

Finally, when a probationer from the narrative interviews was asked through a postinterview questionnaire how much of an impact PWR's with CJ staff had had on his life, he commented:

Probationer 1: A massive impact in my life, as it was the first time in my life that I managed to stay clean for two years and four months. (It was the) first time anyone put their trust in me and gave me a chance to express my assets.

Again, this highlights not only the importance of probation staff possessing a belief in their probationers, but demonstrates the need to actively communicate this to probationers. By integrating relationship skills and the theories that underpin the working relationship within initial training as well as creating opportunities for existing staff to develop their skills through reflective practice, staff may be less inclined to reduce their faith in the relationship between practitioner and probationer.

The benefits of re-centralising the PWR within correctional work will encourage staff to invest the time in developing PWR's, providing them with ways they can effectively use 
the limited time they have to create a climate for change. As Ansbro (2008) argued, time developing a rapport and building a PWR with an offender is an intervention in itself and "time well spent." This time will not only increase the likelihood of positive change in the individual, but have an impact on their levels of motivation and compliance.

\section{Conclusion}

To conclude, the findings from this pilot study reiterated the importance of a PWR between practitioner and probationer. The emerging findings suggest that a combination of "assist, advise, and befriend" and "confront, challenge and change" may be more effective when working with probationers to encourage positive changes and address offending behaviour. From the pilot study, it was emphasised that the attributes of honesty and respect were particularly significant for both probationers and probation staff. Further to this, the results highlighted the need for practitioners to not simply possess a genuine belief in the probationer and their ability to change, but to demonstrate this actively within their work. It is hoped that further exploration in this area through my doctoral work will strengthen these findings and continue to emphasise the importance of "the relationship" within correctional work. 


\section{References}

Annison, J., Eadie, T., \& Knight, C. (2008). People first: Probation officer perspectives of probation work. Probation Journal, 55(3), 259- 271.

Ansbro, M. (2008). Using attachment theory with offenders. Probation Journal, 55(3), 231-244.

Atkinson, R. (1998). The life story interview. London: Sage.

Barry, M. (2007). Listening and learning: The reciprocal relationship between worker and client. Probation Journal, 54 (4), 407-422.

Barry, M. (2000). "The Mentor/Monitor Debate in Criminal Justice: "What Works" for Offenders", British Journal of Social Work, 30, 575-95.

Bibby, P. (1976). Can college educate and train social workers? Probation Journal, 23(1), 2-7.

Bonta, J., \& Andrews, D. A. (2007). Risk-need-responsivity model for offender assessment and rehabilitation (Corrections Research User Report No. 2007-06). Ottawa, Ontario: Public Safety Canada.

Bordin, E. S. (1979). The generalizability of the psychoanalytic concept of the working alliance. Psychotherapy: Theory, Research \& Practice, 16(3), 252-260.

Bourgon, G., Gutierrez, L., \& Ashton, J. (2011). The evolution of community supervision practice: the transformation from case manager to change agent. Irish Probation Journal, 8, 28-48.

Chui, W.H. (2003). "Experiences of probation supervision in Hong Kong: Listening to the young adult offenders", Journal of Criminal Justice: An International Journal, 31 (6), 567577.

Clark, M.D. (2005). Motivational Interviewing for Probation Staff: Increasing the readiness to change. Federal Probation, 69(2), 22-28.

Copsey, M. (2011). The offender engagement programme, an overview from programme director, Martin Copsey. Retrieved November 20, 2011 from http://www.essexprobationtrust.org.uk/doc/The Offender Engagement Programme 0 verview July 11.pdf

Dowden, C., \& Andrews, D. (2004). “The importance of staff practice in delivering effective correctional treatment: a meta-analytic review of core correctional practice." International Journal of Offender Therapy and Comparative Criminology, 48(2), 203-214.

Elvins, R., \& Greena, J. (2008). The conceptualization and measurement of therapeutic alliance: An empirical review. Clinical Psychology Review, 28 (7), 1167-1187.

Forbes, D., \& Reilly, S. (2011). “Using attachment theory with offenders by Maria Ansbro". Probation Journal, 58(2), 167-171 
Gregory, M.J. (2010). "Reflection and Resistance: Probation practice and the ethic of care” British Journal of Social Work. 40(7), 2274-2290.

Ilgen, M.A., McKellar, J., Moos, R., \& Finney, J.W. (2006). Therapeutic alliance and the relationship between motivation and treatment outcomes in patients with alcohol use disorder. Journal of Substance Abuse Treatment, 31 (2), 157-162.

Labov, W., \& Waletzky, J. (1967). "Narrative analysis; oral versions of personal experience", Journal of Narrative and Life History, 7(1-4), 3-38.

Lambert, M.J., \& Barley, D.E. (2001). Research summary on the therapeutic relationship and psychotherapy outcome. Psychotherapy: Theory, Research, Practice, Training, 38 (4), 357-361.

Martin, D.J., Garske, J.P., \& Davis, M.K. (2000). Relation of the therapeutic alliance with outcome and other variables: A meta-analytic review. Journal of Consulting and Clinical Psychology, 68, 438-450.

Maruna, S. (2000). Making Good: How ex-convicts reform and rebuild their lives. Washington: American Psychological Association.

Miller, W.R., \& Rollnick, S. (2002). Motivational Interviewing: Preparing people for change (2nd Ed). New York: Guildford Press.

Newman, J., \& Nutley, S. (2003). Transforming the probation service: "what works", organisational change and professional identity. Policy and Politics, 31(4), 547-63.

NOMS (2010). Offender Engagement Programme News. URL. Retrieved on September 21, 2010 from http://npintranet.probation.gsi.gov.uk/documentlibrary/documents/summary report/stakeholder.doc.

NOMS (2011). Practice Framework: National Standards for the Management of Offenders for England and Wales. Retrieved January 20, 2012 from http://npsintranet.probation.gsi.gov.uk/document library/Documents/practice frame work national standards draft.pdf.

Partridge, S. (2004). Examining case Management Models for Community Sentences. Online Report 17/04: Home Office.

Reason, M. (2010). Mind maps, presentational knowledge and dissemination of qualitative research. Realities Working Paper: Manchester.

Rex, S. (1999). Desistance from offending: experiences of probation. Howard Journal of Criminal Justice, 38(4), 366-83.

Robson, C. (2002). Real World Research: A resource for social scientists and resources. Oxford: Blackwell Publishing.

Rossa, E.C., Polascheka, D.L.L., \& Ward, T. (2008). The therapeutic alliance: A theoretical revision for offender rehabilitation. Aggression and Violent Behavior,13(6), 462-480. 
Stewart, L., \& Picheca, J.C. (2001). Improving offender motivation for programming. Living Skills and Family Violence Prevention Programs. Forum of Corrections Research, $13,18-20$.

Tagg, S. K. (1985). “Life story interviews and their interpretation.” In M. Brenner, J. Brown and D. Canter (Eds.) The Research Interview: Uses and Approaches. London: Academic Press.

Ward, T. (2002). The Management of Risk and the Design of Good Lives. Australian Psychology, 37(3), 172-179.

Worrall, A., \& Hoy, C. (2005). Punishment in the community: managing offenders, making choices. Devon: Willan.

Young, B., \& Tardif, C. (1988). Interviewing: Two sides of the story. Paper presented at the Annual Meeting of the American Educational Research Association, New Orleans, LA, April 5-9th 1988. ERIC, Resources in Education (RIE). 